\title{
La escritura del duelo, de Victoria Eugenia Díaz Facio Lince (2019). Ediciones Uniandes - Universidad EAFIT, $282 \mathrm{p}$.
}

DOI: $10.17230 /$ co-herencia.17.33.10

Clemencia Ardila J. Universidad EAFIT - Medellín aardila@eafit.edu.co

A la lectura de La escritura del duelo de Victoria Eugenia Díaz Facio Lince -psicóloga, magíster en Ciencias Sociales y doctora en Humanidades; profesora e investigadora de la Universidad de Antioquia-, se nos introduce con un epígrafe del escritor español Francisco Umbral:

Cada cual se queda en su muerte, para siempre. La muerte es distancia, sólo distancia.

Y sólo de mí puedes vivir ahora, de tanto como en mí habitaste, hijo.

Y sólo de ti puedo vivir. Sólo está vivo de mí lo que está vivo de ti: el recuerdo.

Con estas palabras se nos anuncia el asunto del cual se trata este libro, el duelo por la muerte de un ser amado, y la fuente de la que se nutren las palabras de la autora: la literatura y, más específicamente, las memorias de duelo, una de las variantes de la escritura funeraria a través de la cual se trata "de reconstruir y dar sentido a una experiencia de pérdida y sufrimiento" (2019, p. 85). Definición que se nos propone prontamente, pero que se resemantiza en cada una de sus páginas y adquiere entonces nuevas dimensiones significativas. Las memorias de duelo son también narraciones de naturaleza autobiográfica donde el doliente plasma todo el vacío y la tristeza que causa la ausencia de alguien amado; esos relatos a través de los cuales se cumple una suerte de ceremonia simbólica como respuesta a esa necesidad de reorganizar la vida después de la muerte del otro; relatos íntimos y emotivos que testimonian el dolor, la tristeza y la soledad que embarga a sus autores por la ausencia del padre, la madre, un hijo o el compañero de vida. 
Narraciones, además, de las que poco se ha dicho en los medios académicos y acerca de las cuales circulan algunos comentarios generales que poco o nada dicen de sus especificidades, de su función simbólica y social, de su vínculo indisoluble con la literatura. Este libro subsana tal carencia y, en esa dirección, se constituye en una fuente de consulta importante para estudiosos e investigadores, para legos y expertos, pues más allá de los saberes que aquí se reúnen -el psicoanálisis, la psicología, la filosofía, la literatura y la antropologíapara analizar las memorias de duelo, nos ofrece un panorama amplio acerca de la escritura funeraria, de sus funciones culturales, sociales y, lo más importante, en relación con el individuo. Además, sin perder la rigurosidad que acompaña a la investigación de la que se nutre este libro, la autora no desconoce la importancia de presentar las nociones y planteamientos de cada una de estas disciplinas de una manera didáctica y clara.

El libro es producto de un arduo trabajo de investigación, con el cual su autora se hizo merecedora de la máxima distinción otorgada a una tesis doctoral y continúa por la línea temática que orientó sus trabajos previos acerca de la vivencia de una enfermedad mortal, la desaparición forzada de seres amados y el destierro violento de los lugares de apego. Su experiencia para tratar estos temas, difíciles por sus implicaciones psicológicas, políticas y sociales, es pues fruto de un trabajo prolongado. Cabe anotar que no es usual que el duelo y la disrupción que ocasiona la muerte de un ser amado se constituyan en objeto de investigación, pero Díaz Facio Lince asumió este reto y el resultado es un libro novedoso y creativo; potente en sus propuestas teóricas y analíticas; sólido en sus procesos metodológicos y, si se me permite la expresión, bello y conmovedor, rasgos poco usuales en los contextos académicos donde la excelencia, la novedad y lo interesante es lo que se suele resaltar. Pero estos dos adjetivos apenas alcanzan para dar cuenta de la factura impecable de este libro, para señalar cómo la autora se aproxima de manera rigurosa, sí, pero también con su sensibilidad, a un asunto tan difícil de analizar como las memorias de duelo. El siguiente es un ejemplo, entre muchos otros, de sus comentarios hermenéuticos acerca de las metáforas que, en este caso, configura Piedad Bonnett para describir a su hijo cuando este regresa de un viaje "con la nariz perfilada de 
los moribundos y una mirada hueca, totalmente opaca, que parece ir hacia adentro, prescindir del mundo exterior" (citada por Díaz Facio Lince, 2019, p. 169). Las palabras de Bonnett encuentran una lectora cuya competencia analítica va de la mano de una comprensión emotiva; a renglón seguido, Díaz Facio Lince dice:

Con esta descripción, con la que evoca el rostro y la mirada vacía de aquellos que están próximos a morir, la autora anticipa en el relato la pérdida definitiva que está por ocurrir. A esta conmoción causada por un rostro que se torna en anuncio de la muerte, se suma el deterioro progresivo del estado anímico y mental de Daniel que evidencia que "el fuego voraz de la locura" (p. 58) empieza ya a despertarse en su cuerpo. Con esta nueva metáfora que alude a elementos de la naturaleza, muestra cómo para ella la enfermedad mental de Daniel no representa solo un desorden orgánico que afecta los procesos cerebrales; es, sobre todo, una entidad violenta y destructora; una llama que se aviva poco a poco en el cuerpo de su hijo hasta que, convertida en incendio incontenible, termina por devorarlo (2019, pp. 169-170).

Como objetivo investigativo Díaz Facio Lince se propone responder a los interrogantes acerca de la función de la escritura sobre la muerte, de los procesos de configuración narrativa del duelo y la disrupción, así como sobre las propuestas de sentido que respecto a dicha vivencia se cifran en las obras dedicadas a tal fin. A estos dos asuntos se refieren cada una de las partes en que se divide el libro, a saber, Duelo, muerte y escritura, de naturaleza teórica e histórica, y la segunda, Las memorias de duelo: proposiciones y sentidos de la muerte escrita, que además de mostrar los rasgos que le son propios a este tipo de escritura, analiza un corpus importante de memorias, doce en total, publicadas en el período 2006-2015 y, como cierre del apartado, nos ofrece una lectura interpretativa de dos obras, Lo que no tiene nombre de la colombiana Piedad Bonnet y La hora violenta, del español Sergio del Molino. Ambas publicadas en el 2013 a raíz de la muerte de un hijo.

Los aportes del psicoanálisis, la psicología, la filosofía, la antropología y los estudios literarios se articulan en este libro para "lograr una comprensión más amplia -que trascienda una mirada exclusivamente psicológica- de los fenómenos de la vida individual y social en los que la pérdida es una experiencia central” (2019, p. 17). Este propósito de la autora se observa de principio a fin en el libro, aunque ello no impide que tres disciplinas dialoguen de manera 
preponderante: el psicoanálisis, en su condición de teoría sobre la vida psíquica, aporta la fundamentación teórica para definir dos nociones centrales, duelo y disrupción; la teoría literaria provee el marco conceptual para definir los alcances temáticos y pragmáticos de las memorias de duelo como modalidad de las narrativas del yo y, por último, la hermenéutica reflexiva, con énfasis en la teoría de la narración de Paul Ricœur, de una parte, es la vía elegida para comprender los nexos entre el sentido de un relato y la existencia humana y, de otra, es la perspectiva desde la cual se analizan las memorias de duelo que constituyen el corpus de estudio.

La amplia bibliografía objeto de revisión en este estudio, la lectura crítica que ofrece de los desarrollos conceptuales y metodológicos de cada uno de los términos en cuestión y, por supuesto, sus propias disquisiciones, son otras de las virtudes de este texto que se muestra a su vez como una suerte de estado del arte acerca de nociones como muerte, duelo y disrupción y, simultáneamente, como un nuevo entramado teórico desde el cual es posible leer, comprender e interpretar las memorias de duelo. Así, por ejemplo, en el capítulo dos de la primera parte del libro, de la mano de autores como Philippe Ariès y Armando Petrucci se nos habla de diferentes concepciones acerca de la muerte: en la primera Edad Media europea, la muerte amaestrada, denominación bajo la cual se enuncia la idea "de que la muerte era el destino colectivo de la especie, con el consuelo certero de la inmortalidad del alma" (p. 69); en los siglos XI y XII se le confiere un sentido más personal y entonces la muerte propia traza el camino hacia la particularización de la vida y su final; en los siglos XVIII y XIX, de la mano del Romanticismo y de los sentimientos y el afecto por el otro, la muerte ajena se exalta por medio de monumentos y formas diversas de escritura. El fin del siglo XIX y el racionalismo imperante transforma radicalmente la concepción de la muerte y esta se torna prohibida, negación de la finitud y afán por lograr a través de la ciencia su prolongación. El horror de la Primera Guerra Mundial, antes que eliminar el velo que cubre la muerte, trajo consigo la retórica del patriotismo como una estrategia para homogenizar a los caídos bajo el rótulo de combatientes y héroes. Como una forma de transgredir la prohibición de otorgar un nombre propio y una historia de vida al individuo, surgen "un abundante flujo de escrituras privadas, 
espontáneas, coloridas que se filtran como expresión de una cultura diferente de la oficial" (p. 75), origen de las memorias de duelo. Esta apretada síntesis solo pretende mostrar cómo la autora, en este recorrido antropológico del sentido de la muerte en el mundo occidental, además de dar cuenta de la variación conceptual del término muerte, también demuestra la función social y cultural de la escritura funeraria. De esta forma reúne diversas disciplinas y construye para el lector un marco conceptual a partir del cual se comprende el lugar y la función en nuestro tiempo de las memorias de duelo.

Otro de los rasgos para destacar tiene que ver con el lugar que ocupan las memorias de duelo en las ciencias sociales. Así, de la mano de autores como como Ricœur, en la hermenéutica; Alberca, en los estudios literarios, y Bal, en los estudios culturales, Díaz Facio Lince las clasifica como formas literarias y memorias narrativas en las que confluyen lo íntimo y lo social. Rasgos, además, que les otorgan un doble estatuto: son una de las modalidades de las denominadas narrativas del yo, de las que hacen parte las autobiografías, los diarios y las autoficciones, y son también una expresión de la memoria cultural. La segunda parte de este texto, de carácter analítico, se dedica entonces, en el capítulo 3, a presentar obras pioneras del género, como la del escritor inglés C. S. Lewis, Una pena en observación (1961), y a describir doce memorias de duelo publicadas en el mundo occidental durante el período 2006-2015. Para tal fin, la autora propone tres criterios: el vínculo con el ser perdido (padres, esposos e hijos); el modo en que acontece la muerte (accidente, suicidio, enfermedad, homicidio, desaparición forzada) y, por último, la función y sentidos de la escritura. Estos rasgos se analizan en doce obras de la literatura colombiana, española, argentina, estadounidense e inglesa. De este modo, por las páginas del capítulo 3 desfilan obras en las que se narra la muerte del padre, El olvido que seremos de Héctor Abad Faciolince, a causa de un homicidio; de la madre, Aparecida, de Marta Dillon, por desaparición forzada; Un mar de muerte de David Rieff, después de una larga enfermedad; como también la de un hijo que se suicida, Lo que no tiene nombre de Piedad Bonnett y Cuando muere el hijo, de Abel Posse, para citar solo algunas. El tercer criterio, las intenciones comunicativas y significativas que acompañan la escritura, resulta interesante, por cuanto el análisis de las obras muestra cómo las 
anima, de una parte, un propósito íntimo, "ordenar y transmitir una experiencia de sufrimiento" y, de otra, uno social, "preservar la memoria pública" (p. 110) de los seres amados. Pero, como bien lo anota Díaz Facio Lince, esta intención general se acompaña de otros deseos, particulares de cada autor, razón por la cual se detiene en cada una de las doce obras para mostrar, por ejemplo, cómo Cervera reconstruye, a la par que la vida de su madre, la memoria de los vencidos en la Guerra Civil española, o el caso del colombiano Carlos Framb, cuya escritura se dirige a defender el derecho de asistir y ayudar a morir a su madre como un acto de amor.

Los tres últimos capítulos del libro se dedican al análisis interpretativo y riguroso de dos obras: Lo que no tiene nombre de la poeta colombiana Piedad Bonnett y La hora violeta del periodista y escritor español Sergio del Molino, no sin antes ofrecer en el capítulo 4 el marco teórico y metodológico que guiará la lectura, la perspectiva hermenéutica reflexiva de Paul Ricœur. La lectura interpretativa se realiza, tal como lo propone el autor francés, a partir de las estrategias que sus autores implementaron en el proceso de su configuración: en el caso de Bonnett, los epígrafes que anteceden la narración de la enfermedad y suicidio de su hijo a los veintiocho años; en el de Del Molino, por los ejes espacial y temporal en los que se desarrolla el relato de la enfermedad y muerte de su bebé poco antes de cumplir los dos años. La experiencia de lectura de estos dos capítulos concita de manera enfática la sensibilidad del lector a quien le es imposible permanecer imperturbable ante cómo la autora devela en sus significados la expresión de impotencia que embarga a una madre y a un padre en el momento de elegir las palabras para narrar la ausencia del hijo; para comunicar esa fractura de la vida a causa del suicidio y la enfermedad.

En suma, La escritura del duelo de Victoria Eugenia Díaz Facio Lince es, además de interesante, inquietante, por la reflexión que concita el recorrido por las diferentes maneras en que a lo largo del tiempo hemos afrontado la muerte y sus ritos, y porque nos recuerda la función íntima, social y cultural de las memorias de duelo en una época en la que las vivencias de la pérdida de una madre, un padre, un cónyuge o un hijo parecen borrarse en el laberinto de las urgencias económicas, políticas y de producción de nuestra sociedad. 
Es entonces cuando la palabra poética nombra lo innombrable; es el momento en el que la escritura se erige con fuerza y dice, como lo hace Umbral y nos lo recuerda Victoria: "Se puede. La muerte en torno, la fiebre ondeando sus fatigadas banderas, el miedo. Pero se puede vivir -y esto es lo atroz- en la entraña misma del horror. También el horror puede llegar a ser de alguna manera confortable" (citado por Díaz Facio Lince, 2019, p. 250) 【 